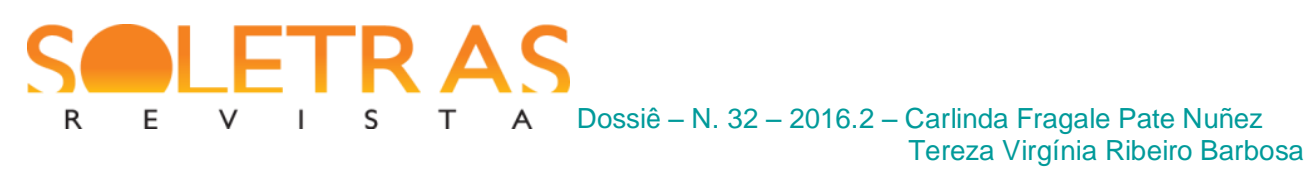

\title{
Ismene, princesa de Tebas e o páthos (pós-)moderno
}

\author{
Carlinda Fragale Pate Nuñez (UERJ) \\ Tereza Virgínia Ribeiro Barbosa (UFMG)
}

\begin{abstract}
Resumo: A tragédia de Ismene, princesa de Tebas, de Pedro de Senna (com estreia em 2007 e publicação em 2013), nos ocupará nesse estudo. A peça levou o $1^{\circ}$ prêmio, por júri popular, na "Seleção Brasil em Cena 2006", concurso de dramaturgia para novos autores, promovido pelo Centro Cultural Banco do Brasil e foi encenada, no ano seguinte, sob a direção do premiado Moacir Chaves. Nosso método, a abordagem intercultural, se enquadra numa modalidade específica de comparativismo que, sem desprezar correlações e paralelismos, privilegia a função das intempestividades anacrônicas adotadas como procedimento estético e com rentabilidade artística. Trata-se de depreender um saber social que se exprime no discurso, no plano das contextualidades culturais. Além do mencionado aparato teórico, vamos igualmente lançar mão da teorização de Warburg e de seu conceito de Pathosformeln, isto é, das "fórmulas afetivas".
\end{abstract}

Palavras-chave: Pedro de Senna, Sófocles, Ismene, recepção clássica.

O teatro brasileiro de tema greco-romano reúne um repertório expressivo de peças trágicas e cômicas, tendo-se consolidado, ao longo do século XX, através de obras que se tornaram emblemáticas tanto da eficaz adaptabilidade do clássico à posteridade quanto de engenhosas formas de absorção do antigo pela dramaturgia latino-americana. Em sua maioria, as reapropriações brasileiras da herança clássica se prestaram a reformulações radicais, quase desfigurações da matriz grega ou romana, devidas à frequente nacionalização das problemáticas, à mudança de nomes das personagens e à hibridação de formas.

Jorge Andrade reencarnou Antígona em Mariana, de Pedreira das Almas (1958); Nelson Rodrigues reinventou a saga dos atridas, em Senhora dos afogados (1947), a partir da miscigenação da Electra grega com mitos da cultura brasileira. Temos duas reencarnações de Medeia: como Joana, em Gota d'água (1975), de Chico Buarque e Paulo Pontes, e como homônima da heroína euripidiana, a protagonista vive o drama de ser negra, na peça de Agostinho Olavo, Além do rio (1961). Carlos Henrique Escobar, ainda que menos conhecido e estudado, cria um Ramon Filocteto americano (1977), uma Ana Clitemnestra (1986), uma José Medeia (Medeia masculina) (1998) e uma Antígone América (escrita aos 17 anos, mas publicada em 1962, aos 29). Talvez tenha sido o dramaturgo que mais produziu peças de extração mítica, para o teatro brasileiro. Destaca-se, ainda, neste repertório, a Trilogia perversa (1986), adaptação da maldição dos Atridas por Ivo Bender ao ambiente da imigração alemã no Rio Grande do Sul, à virada do século XIX para o XX.

A comédia conta com títulos de Ariano Suassuna, Guilherme de Figueiredo e Augus to Boal, realizações que consagraram a linhagem dramática no Brasil e conquistaram a aclamação da crítica e do público.

Confirmam-se, no Brasil, a já consabida presença do clássico nos palcos atuais e a tendência universal do teatro a revisitar sua própria memória, o constante retorno às suas fontes, formas e suas personagens mais notáveis. 
Foram, entretanto, necessários exatos 1.565 anos - mais de um milênio e meio - para que Ismene fosse, em terras brasileiras, retirada das sombras que lhe couberam como herança do glorioso teatro ateniense. Nos trópicos, a maldição dos labdácidas foi mais pesada para a irmã de Antígona, que sobreviveu inglória na sobrevida pós-clássica. A tradição a colocou no pedestal das personagens secundárias, como "símbolo da insegurança e da perplexidade. [Daqueles que] Não têm força e nem coragem para ajudar e nem mesmo para ajudar-se" (BRANDÃO, 1991: 617). Ismene jazeu bastante ignorada, objeto predileto de indiferença, incapaz de sugerir uma nova trama trágica. Talvez porque beirasse ao patético e se afastasse da violência trágica tão impactante de outras personagens mais fortes. Neste conjunto de tendências negativas, pulsa, entretanto, algo de intrigante: poderia Ismene fornecer algum sentido para suas ações, ou despertar qualquer interesse de páthos $(\pi \alpha \dot{\alpha} \theta \varsigma)$ ) violento para novas plateias no novo mundo? Longe do teatro sério, a pobre Ismene não alcança nem mesmo a ribalta do cômico? Nenhuma importância além de coadjuvante de Antígona? Veremos que não. Em outras terras, de modo suave, Ismene se apresenta em muitos textos: um monólogo, do poeta grego contemporâneo Yannis Ritsos (Grécia,1993); uma adaptação de Milena Bogavac (Sérvia, 2014), uma outra de Jeremy Menekseoglu (Estados Unidos, 2011), outra de Miriam Wolodarki (Suécia/ Estados Unidos, 2010), e também uma de Emma GoldmanSherman (Antigona's sister, Estados Unidos, 2014)....

A filha de Édipo manteve-se como signo de uma ausência, presença depreciada, na tradição a que pertence, deixando os brilhos para Antígona. Curioso é pensar que Ismene cumpre o ideal grego de mulher proclamado pelo antigo provérbio:

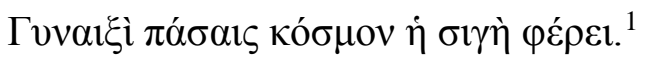

O silêncio dá beleza para todas as mulheres.

Nas terras brasileiras é prática comum esquecer Ismene. Duas peças de Jorge Andrade, Pedreira das Almas (1957) e Confrarias (1969) que recuperam o mito de Antígona, Ismene sequer aparece. Mas, felizmente, o procedimento se modificou na primeira década do século 21. Quase simultaneamente, vem à cena Doce Ismênia, de Rita Clemente (2011) e A tragédia de Ismene, princesa de Tebas, de Pedro de Senna (com estreia em 2007 e publicação em 2013), que nos ocupará nesse estudo.

Foi Pedro de Senna que percebeu exatamente nesta condição de sombra, na existência fantasmal de figurante melancólica, a situação ideal para fazer da silenciosa Ismene a protagonista de uma tragédia moderna e pós-moderna. É pois a vida em negativo, como significante ao qual não se agregou nenhum significado que traduz a patética insignificância, a imagem da nulidade absoluta que a promoveu à exata situação de protagonista da atualidade que versará este ensaio.

\section{Intertextualidade e transferência cultural}

É nesta situação nublada e pelo olhar de Pedro de Senna que Ismene ressurge como lua nova, no firmamento do teatro brasileiro de tema mítico. Ismene arrebata o $1^{\circ}$ prêmio, por júri popular, na "Seleção Brasil em Cena 2006", concurso de dramaturgia para novos autores,

\footnotetext{
${ }^{1}$ Citado a partir de Renzo Tosi, Dicionário de Sentenças Latinas e Gregas, p. 632; o provérbio é encontrado no Ajax de Sófocles (v. 293); nos Monósticos de Menandro, (frag. 139 Jäkel); em Tucídides, 2, 45, 2 e no Rudens de Plauto (v. 1114)
} 
promovido pelo Centro Cultural Banco do Brasil. A peça foi encenada, no ano seguinte, sob a direção do premiado Moacir Chaves.

Pedro de Senna, nascido no Rio de Janeiro em 1975, mas residente na Inglaterra desde 2001, angariou um respeitável currículo ligado às artes cênicas e ao dramático. É ator, dramaturgo e diretor de teatro. Começou a atuar em 1993, depois de formado em Desenho Industrial. Fez um Mestrado em Teatro (texto e produção) nos Estados Unidos, e desde então se dedicou à cenografia, à interpretação, à criação de peças e organização de workshops, no Brasil e na Inglaterra. O fato de se ter especializado em tradução e adaptação anuncia um processo criativo que já contém uma dimensão crítica em sua arquitetônica.

Com esta bagagem, o dramaturgo concebe um novo drama muito marcado pela brasilidade e bastante comprometido com o gênero original que teve seu apogeu na Ática, pontos que desenvolveremos paulatinamente nesse relato. De início apenas alertamos que o texto é dividido em partes retomadas de forma clássica, ou seja, as cenas são marcadas como prólogo, párodo, cenas/episódios, odes corais e êxodo.

O ponto de partida do brasileiro situa-se em um verso proferido por Hemon, na

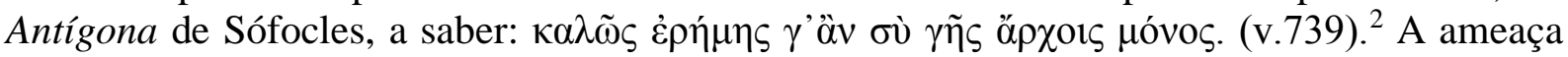
velada do filho de Creonte a seu pai, na peça brasileira, converteu-se em profecia realizada que o coro proclama: Pobre Tebas/vítima de cerco/ de um rei louco/ de generais tristes / de uma casa morta/ (SENNA, 2013: 24) ${ }^{3}$

Contudo, este corpo vazio da cidade - e de Ismene - está na iminência de uma invasão. Creonte expia, como demente, a responsabilidade da morte de todos os seus familiares. Sua função de governante foi delegada a generais que tomaram as rédeas de uma pólis deserta de homens e repleta de fantasmas do passado. Sem poder, sem filhos, sem mulher e sem juízo, o rei vive acossado por espectros.

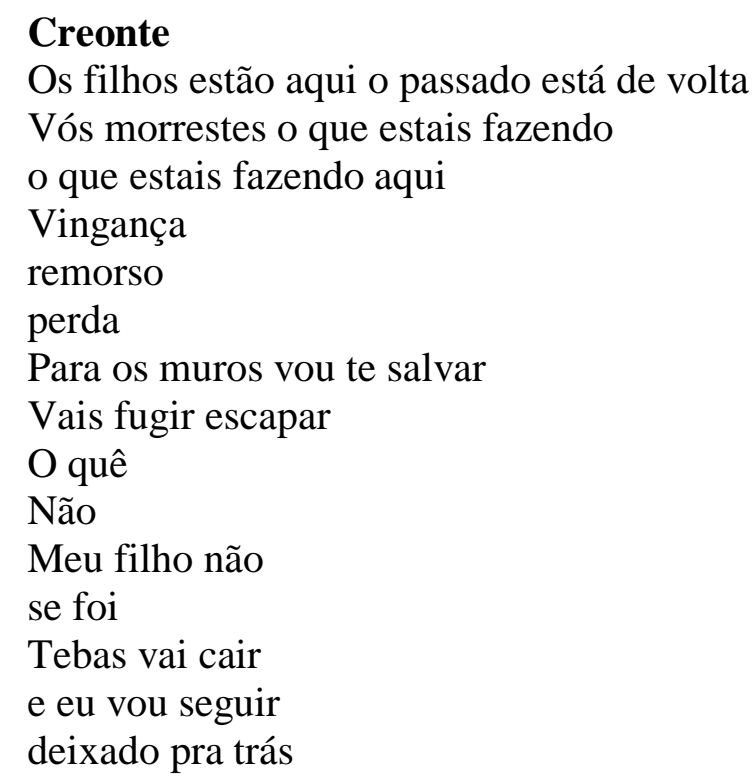

\footnotetext{
${ }^{2}$ Nosso texto grego de referência para Antigone foi a edição de Mark Griffith, 1999, Cambridge. É do mesmo Griffith, em parceria com Reginald Gibbons, a tradução: "You'd do well as the single ruler of some deserted place"; em português, "Muito bonito, numa terra deserta, sozinho, mandarias bem." (todas as traduções de Antígona do grego para o português são de nossa autoria).

${ }^{3}$ A partir daqui, as citações da peça serão referidas pela abreviatura do título (IPT), seguida da página, na edição de 2013.
} 
dos muros

Tebas vai cair

Eu sei

Não

Tebas vai cair

(IPT, 2013, p. 22-23)

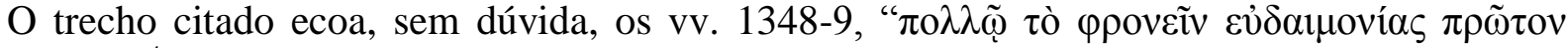

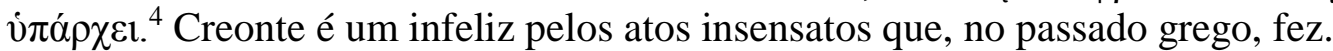

Após o prólogo, em párodo típico, o coro de mortos tebanos lamenta o infortúnio de ver, mais uma vez, o cerco da cidade de Tebas. Ao final da ode coral, abre-se o primeiro episódio com uma cena em que Ismene se aconselha com Tirésias, que encara com ceticismo seus outrora prestigiosos dons proféticos: a voz da resistência, no passado, se apresenta como arauto da desistência no presente (IPT: "eu não quero mais", p. 28; "estou cansado disso / tudo / eu quero que se acabe / paz", p. 29-30). O velho adivinho reconhece Ismene como “intocada pela maldição" (p. 26). Todos os labdácidas estão mortos, à exceção de Ismene, que é colocada num dilema: para salvar a cidade do inimigo, deve entregar-se a um rei estrangeiro e gerar um herdeiro. É neste ponto que signos correlatos - cidade e membro da família real remanescente - se unem numa mesma função de significados dobrados, expediente frequente na apropriação dos clássicos pelos brasileiros: a Tebas residual está vazia de homens e será invadida; Ismene, a semente sobrevivente de Édipo deverá ser fecundada por um invasor a fim de preservar a estirpe. O procedimento se comprova, por exemplo, com o verso que se repete ligeiramente modificado na boca da protagonista: " $\mathrm{O}$ trono de Tebas não será usurpado" (...); “O meu corpo não será usurpado" (p. 36). Une-se, desse modo aquilo que Sófocles preconizou abominável; aquilo que, gerado no interior da cidade, a destruiu; aquilo que pode ser considerado como resultado dos atos perpetrados por Antígona e que se resume na mistura de interesses, isto é, no conflito e na indefinição do que fosse o público e o privado; promiscuamente, eles estão no mesmo lugar.

Todavia, a peça, em sua ousada atribuição de éthos trágico à patética Ismene, retira a figura de um sono milenar e a qualifica para a detecção de questões de difícil identificação na peça sofocliana, mas que podem ser a referência mais evidente para a construção da nova personagem. Ismene - numa espécie de crescendo trágico - assumirá o caráter de sua mãe, Jocasta, enquanto prêmio:

Ao anunciar meu leito nupcial

Como os generais tebanos agora querem

Como o leito de minha mãe foi anunciado

(...)

Não serei a puta da cidade

(IPT, p. 39)

A puta da cidade

Princesa à venda

\footnotetext{
${ }^{4}$ Todas as traduções de Antígona do grego para o inglês são da autoria de Griffith, em parceria com Reginald Gibbons: "Good sense is the first principle of happiness.", em português: "Em muito, ajuizar-se vem primeiro que a felicidade".
} 
Como foi minha mãe

Deu no que deu

(IPT, p. 63)

Emancipada e capaz de afirmar que "meu corpo e sangue são só meus" (pp. 45, 51, 66, 99), essa heroína recusa a maternidade e opta pelo exílio e pela deambulação com Tirésias. Ela é tradição clássica, é acumulação trágica, magma de Ismene, Jocasta e Medeia ${ }^{5}$, antes mesmo que os filhos lhe nasçam.

\author{
... muitas vezes \\ eu quis morrer \\ com nada mais por que viver... (Senna, 2013, 38) \\ ... e se um filho vier quando o filho vier \\ Vou matá-lo \\ Não deixá-lo viver um filho maldito \\ (IPT, p. 90) \\ Manterei viva a Cidade dos Sete Portões \\ Mesmo que tenha de matar meu filho não nascido... \\ (IPT, p. 93)
}

O dramaturgo expressa a fusão dessas heroínas míticas, colocando como fala de Ismene fragmentos de versos adequados à filicida euripidiana, a qual abre mão da principal função feminina na pólis, de fato,

Birth is a natural physiological process, but for human beings it is also a social event. Culture intervenes in countless ways to shape and structure the experience. (...) Giving birth is not so much a "natural" event as a "cultural construction" (or, in our case, a choise between cultural constructions). As a consequence, the study of the way in which a particular society perceives and manages childbirth reveals fundamental aspects of its cultural and social values. Such a study is especially valuable for classical Greece, where women's central role was a childbeares and little other evidence exists for them. (DEMAND, 1994:1) ${ }^{6}$

\footnotetext{
${ }^{5}$ Euripides, Medeia, v. 79-793: ఝ̆

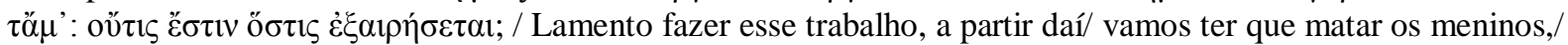
os meus. Não há ninguém para os salvar. (tradução Truสersa, Texto de David Kovacs)/ Once that's done, the next thing I must do chokes me with sorrow. I will kill the children my children. No one on this earth can save them. (translated by Diane Arnson Svarlien). ${ }^{6} \mathrm{O}$ nascimento é um processo fisiológico natural, mas para os seres humanos ele é também um evento social. A cultura intervém de inúmeras maneiras para moldar e estruturar a experiência. (...) Dar à luz, porém, não é um evento tão "natural" como uma "construção cultural" (ou, no nosso caso, uma escolha entre construções culturais). Como consequência, o estudo da maneira pela qual uma determinada sociedade compreende e lida com o parto revela aspectos fundamentais dos seus valores culturais e sociais. Tal estudo é especialmente valioso para a Grécia clássica onde o papel central da mulher era engendrar, e quase nenhuma outra relevância havia para elas.
} 
Vemos, portanto, que o tecido dramático da peça brasileira se constitui de ressonâncias oriundas de personagens e textos amalgamados. Além de Antígona propriamente dita, de Medeia e Édipo Rei, podemos abranger os Sete contra Tebas de Ésquilo, as Fenícias de Eurípides, para mencionar algumas fontes antigas, às quais se somam citações de Shakespeare e até de Tchekhov. Mas não vamos privilegiar aqui o levantamento da malha intertextual especificamente, que renderia mais que um ensaio. Não nos podemos furtar, todavia, a assinalar algumas estratégias de reapropriação, pela riqueza de processos empregados.

Há evidentes importações dos mais importantes conceitos da cultura trágica dos gregos: são 22 referências à hýbris, como traço da identidade tebana; 25, à voragem sanguínea dos labdácidas, capaz de tornar indistintos, na mesma selvageria de morte, o sexo e a guerra a anunciada invasão da cidadela é reiteradamente referida como "estupro de Tebas" e o "estupro de Ismene", cujo corpo seria o preço pago pela entrada pacífica do inimigo, autodenominada "puta de Tebas"; o castigo tremendo imposto a Creonte - restar só, como único tebano remanescente na Tebas ocupada, um exilado em sua própria terra. A expiação de Creonte, na tragédia moderna, tem dimensões mitológicas, se recobramos o sentido do exílio para o homem antigo, aqui apresentado como desterro às avessas.

Alusões a atitudes covardes ou pusilânimes de Ismene, no repertório antigo, recontextualizadas no quadro da modernidade, trazem engenhosas reinterpretações capazes de converter as acusações do passado em álibis e até motivos para a valorização da mulher condenada pela tradição:

\section{Ismene}

Eu abri mão de minha morte por Tebas e agora

Tebas vai ser tomada

(...) abri mão da morte e

abandonaram a cidade para ser tomada estuprada usurpada

por estrangeiros

como meu sangue seria

(IPT, p. 98-99)

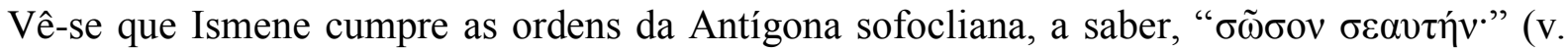

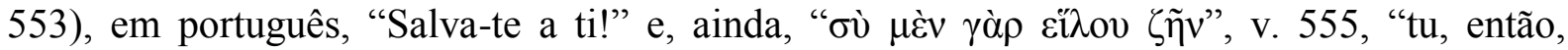
elegeste a vida!"7. Séculos depois, pelas ordens cumpridas, lamenta-se.

Não podemos deixar de referir as situações configurando deslocamentos semânticos, emanações, sutilezas de historicidades, defasagens formais e semânticas. As assimilações deste tipo nos interessam mais, pois constituem um acesso privilegiado à compreensão do que está sendo culturalmente transferido. Em outras palavras, tomamos A Tragédia de Ismene de Pedro de Senna como exemplum para nossa hipótese investigativa: de que o teatro moderno de tema clássico no Brasil constitui um significativo e eficiente canal de transferência cultural, não apenas de repertório temático, mas de valores, questões, imagens, crenças, modos de representação. Se a cada reescritura de um mito ou passagem da historiografia greco-latina corresponde uma reavaliação do presente em que a peça vai ao palco, deve-se levar em conta, também, que a seleção do tema antigo se dá em função dos quadros de referência do presente, e é para este código cultural que o texto antigo se vê transferido.

Através deste raciocínio muito simples, defendemos uma nova abordagem, que leva em conta um terceiro espaço de concentração de sentidos: entre o universo de partida de um

\footnotetext{
${ }^{7}$ Em inglês: "Save yourself!”; “you chose to live".
} 
tema e o contexto de acolhimento (o sistema de recepção), encontra-se um lugar das imbricações culturais especialíssimas, não materializadas na forma de instituições, técnicas e hábitos - em última análise, o material etnológico das relações culturais - , mas os signos trans-históricos ${ }^{8}$, as intermitências culturais e os signos intempestivos ${ }^{9}-$ de um outro tempo que se disjunta do mundo em que ele acontece, aos quais Nicole Loraux denominou "outro tempo" (1993), e Hamlet (Shakespeare, Ato I, Cena 5) já havia definido como o tempo que irrompe "out of joint", o tempo "fora de seus gonzos", "fora dos eixos" - este tempo que se pensa adiante de sua época, ao modo de um anacronismo muito bem controlado. Esta disjunção com relação ao tempo indica que o mundo não é homogêneo, nem há contemporaneidade absoluta: o passado pode avançar, e o presente recuar, movimentos temidos pela História, mas que a arte maneja com sabedoria. A crítica alemã, seguindo as lições de Ernst Bloch (em Erbschaft dieser Zeit, 1935), criou a categoria de Ungleichzeitige "o não-contemporâneo" - para conciliar heterogeneidade e História. Conciliar em que sentido? Admitindo que "todos os materiais da história cultural são, em princípio, reutilizáveis, recicláveis; sobrevivem mais ou menos ativa na história cultural; nada estará definitivamente morto" (MOSER, 1989, p.1-2). Vamos adotá-la para entender o heterogêneo ao nosso tempo que se manifesta no teatro contemporâneo. A tragédia de Ismene, princesa de Tebas, de autoria de um dramaturgo-tradutor, serve idealmente à demonstração de que o teatro de tema clássico, como canal de transferência cultural sui generis, já constitui um tipo de tradução, uma vez que "corresponde à passagem de um código a um novo código" (ESPAGNE, 2003, p. 8).

Nosso método é, portanto, intercultural e se enquadra numa modalidade específica de comparativismo que, sem desprezar correlações e paralelismos, privilegia a função das intempestividades anacrônicas adotadas como procedimento estético e com rentabilidade artística. Trata-se de depreender um saber social que se exprime no discurso, no plano das contextualidades culturais.

Para tanto, vamos apresentar apenas dois exemplos. O primeiro exemplo diz respeito aos deslocamentos formais e semânticos. Solicitamos ao leitor assistir a 4 minutos do espetáculo, ${ }^{10}$ para que tenha uma noção do trabalho dramatúrgico com que estamos lidando..

\section{Intermidialidade e emergência do páthos}

Pedro de Senna e Moacir Chaves, o encenador, adotam uma linguagem cênica inusual. Montam um painel e estipulam um regime discursivo artificiais, ligados a espaços imaginários, como as coleções, os museus, os panteões. Neste painel, as personagens ficam estanques como livros nas estantes das bibliotecas. Os diversos painéis de que se constituem as cenas do espetáculo, evocam as pranchas do Atlas de Imagens "Mnemosyne" de Aby Warburg (2010). A cena exige uma recepção cerebral, que capture a racionalidade que vai sendo apresentada, na contramão do esperado: nada de cenários realistas, de personagens conhecidas que pretendíamos reencontrar: Ismene não é débil, Creonte sim; Tirésias não tem

\footnotetext{
${ }^{8} \mathrm{O}$ conceito salienta o ressurgimento de ideias, práticas, estruturas e representações ao longo de épocas históricas ulteriores àquela específica em que foram produzidas. Não se eleva acima da História, mas também não homogeniza as diferenças numa unidade presumida. Ao contrário, trabalha no interior da História, superando as cadeias de causalidades e a ilusão das continuidades. A irrupção de formas de expressão e de padrões de sensibilidade independentemente de seu momento de origem projeta um tempo trans-histórico capaz de testemunhar o que aí existe de local e universal, atual e intempestivo, da ordem do particular e também da latitude mais ampla do humano.

${ }^{9}$ Intempestivo é “aquilo que não está no tempo próprio; (...) sendo uma manifestação, um ato, um fato que se dá no tempo, não se dá, no entanto, no tempo devido" (D’Amaral: 2003, p. 15).

${ }^{10}$ YOUTUBE - http://www.youtube.com/watch?v=oG9thqjXW1g
} 
o prestígio de antes; o General é um articulador político ${ }^{11}$ preocupado em salvar a própria pele; o Guarda cumpre sua função; o Coro é representado por três mulheres, almas penadas que não interferem na trama. A cena arcaica remete a um mundo primordial, originário, que se comunica com galerias e arquiteturas interiores, semelhantes a arquivos, memórias compartimentadas. Ismene aparece no centro e no alto do cenário, no cerne da constelação, dando-lhe sentido.

Tebas é subalterna aos lugares de memória acionados pelo cenário em painel, chapado, reticulado, atravessado por coordenadas e abscissas. Nele se estruturam realidades arcaicas e contemporâneas, que remetem aos ancestrais e a repertórios de signos.

Este autêntico "cenário com dupla entrada" (tiroir à double entrée, ESPAGNE, 1993) coloca em comunicação dois sistemas culturais distantes no tempo e no espaço; mundos nãocontemporâneos (Ungleichzeitige), mas conectados imaginariamente como construção perspectivada pela posição história, linguística, política de diferentes tipos de atores. Homens do presente interpelados por congêneres de outra era se situam fora do tempo da história, incorporando dimensões da existência humana.

A peça instaura uma temporalidade anterior à própria Grécia. É o tempo mítico, são os eídola (fantasmas), aqui transformados em kolossoí (colossos), com suas propriedades transcendentes e fenomenais (VERNANT, 1993, p. 263-276) que entram em cena. A concepção do texto e do espetáculo recobra o arquetípico. Com isso, não só revalida a supremacia do modelo mítico sobre o natural, para afirmar o heroísmo numa perspectiva da modernidade, como ousa encarnar a verdade natural oposta ao naturalismo, para descobrir afinidades com o primígeno, lá onde germina o trágico.

A exploração do imobilismo cênico corresponde à captura da pura beleza do arquetípico e a uma mobilidade outra, concernente aos estados emocionais fundadores da

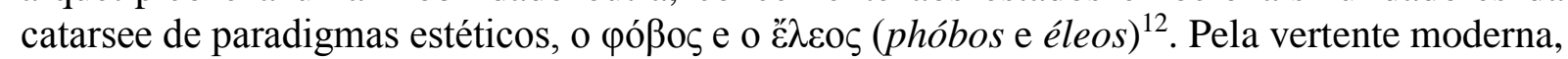
opõe-se ao museológico e afirma-se o arquetípico; pela pós-moderna, celebra-se a autenticidade da ruína. Sem se confundir com qualquer tipo de reconstituição arqueológica, $A$ tragédia de Ismene cultiva o gosto pelos impulsos primitivos e pela regra, a invenção audaciosa e a centralidade do páthos.

A Ismene brasileira, no sistema dramatúrgico constituído, não desmente a tradição a que pertence: o medo, a dúvida, o ceticismo, adquirem uma autojustificação, no horizonte cultural e filosófico em que ela reaparece, já não mais como representante de um éthos acorvadado, característico do feminino na Grécia, mas de um sujeito acossado, num mundo marcado pelo pragmatismo, niilismo, pela reificação das pessoas e dos afetos. Em algumas passagens, este páthos moderno se manifesta, ligado a questões pânicas da atualidade:

\section{Coro}

Esta é a tragédia da dúvida / descrença

(IPT, Ode 7, p. 103)

\section{Ismene}

Eu estava decidida

tinha decidido

estou decidida

a não ter filhos

ou será isto desafiar os deuses

tentar evitar uma maldição

\footnotetext{
${ }^{11}$ O General mente ("Dize / que a princesa / se ofereceu em alegre sacrifício/ casamemto", IPT, p. 82); tem em mente desertar de Tebas com a glória de não ter derramado uma gota de sangue.

$12 \mathrm{O}$ medo e o compadecimento.
} 
que não se pode evitar

que não perdoa

que não se aplaca

que não tem fim

(IPT, Cena 6, p. 88-89)

\section{Tirésias}

Que bem o meu conselho pode fazer não sei nem que bem ele jamais fez

Estou cansado disso cansado disso

Tebas vai cair e pronto

(IPT, Cena 1, p. 27)

Um plano é o que eles têm e isso basta

o que eu vejo e o que eu não vejo não são nada

eu sou só um velho cego

o que eu digo e o que eu não digo não importam

(Id., p.28)

\section{Ismene}

Não posso suportar os muros vazios

os fantasmas de minha indecisão

(IPT, Cena 6, p.102)

\section{Ismene}

Carregar um filho para

carregar uma maldição

isso é pedir demais a qualquer mulher

o novo rei vai querer um herdeiro

exigir um herdeiro

me estuprar por um herdeiro

se estuprar for preciso

(Cena 3, p.46)

Que liberdade temos

mulheres num mundo de homens

homens num mundo de deuses

eles nos tomam domam

prendem

(Id., p.49)

Vivi em delicado

equilíbrio

pelas tempestades

da morte eu tive a coragem

de abrir mão de meus ideais pela minha vida

e não de minha vida por meus ideais

que ideais

vivi uma morte viva

uma vida sem sentido

(IPT, Cena 4, p. 68-69) 
A protagonista está perfeitamente habilitada a uma tarefa que é dupla. A primeira, encarnar o páthos do homem moderno, as afecções da alma despertadas pelo Outro, num mundo cada vez menor e mais ocupado, mais legalista, tecnocrático e produtivista. No horizonte grego, o páthos concerne à "experiência de algo misterioso e assustador, de uma força que está dentro dele, que o possui em lugar de ser por ele possuída" (DODDS, 1985, p. 185). O novo páthos preserva este caráter de sensibilidade conflitiva (está na Sehnsucht dos românticos alemães), mas é Kierkegaard (apud NOVAES, 1987, p. 273) quem mais precisamente o define, na perspectiva da modernidade, como uma aspiração do infinito, esta inquietude que qualificou de "perpétuo esforço para apreender aquilo que se desvanece". Como conceito, traz em sua franja o duplo sentido de passividade e atividade contido no páskhein $(\pi \alpha ́ \sigma \chi \varepsilon ı v)$, sofrer e agir reativamente. Esta dualidade ativo-passiva determina que o páthos provoque certa mobilidade, leve a reagir, em geral, impetuosamente. No caso do páthos trágico, trata-se de uma motivação que, na maioria dos casos, leva a agir de forma bem pensada - o que não quer dizer de forma "ponderada", isto é, "equacionada, matematicamente

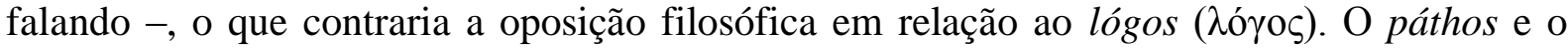
lógos, no âmbito do sentir e do agir trágicos, são, de alguma forma, indissociáveis, seja porque o afeto é verbalizado, seja porque o verbalizado pretende extrapolar a palavra e materializar a emoção

Um verso de Ésquilo sintetiza esta densidade do páthos trágico: " "No sofrer, o saber" (Ag., v. 177) ${ }^{13}$ que ressoa, transportado para a clave moderna, no verso da Ismene brasileira: "A dor ensina às mentes mais fortes fraqueza" (IPT, p.56).

Para compreender a cerebralidade da obra, tem-se de pensar, de alguma forma, como Ismene. É o que diz o Tirésias de Pedro de Senna, em mais de uma oportunidade: "Minha filha, sempre tiveste boa cabeça" (IPT, p. 87); "sempre soubeste quando parar" (p. 26). Aqui a caracterização da antiga mulher sábia, que se cala e mostra pensar bem, tal como afirma o v.

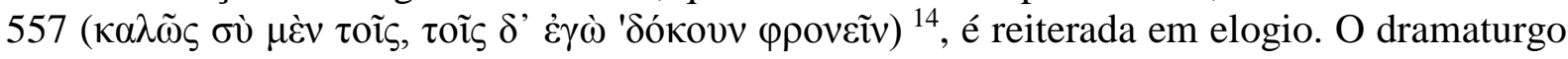
não é ingênuo, ao realçar a racionalidade apregoada para Ismene; ele, porém, retira-a da condição de submissão da grega para dar-lhe a materialidade do ato revolucionário no tipo de enunciação dramática que se lê no texto e se vê no espetáculo.

A Ismene razoável e lógica é anunciada no célebre e hermético verso de abertura de Antígona, traduzido por Nicole Loraux de forma domesticada como "Tu és meu sangue, minha irmã, Ismene, minha querida", o que obriga a admirável helenista a fornecer uma nota, onde consta a tradução que ela considera literal - "Tu és minha querida cabeça fraternal, Ismene", ainda insatisfatório. De fato, o verso de Sófocles guarda um ar épico um tanto antigo para o público ateniense, pois, palavra a palavra, o verso diz: "Ó comum e fraterna cabeça de

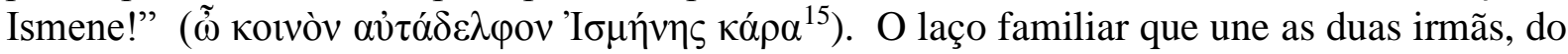
ponto de vista de Antígona, é o pensamento. Quando Ismene demonstra com bons argumentos que é uma temeridade a execução do projeto religioso, Antígona afirma que realizaria o ato piedoso ao preço de praticar qualquer baixeza (Sófocles. Ant.. v. 75, ő $\sigma 1 \alpha \pi \alpha v o v \rho \gamma \eta ́ \sigma \alpha \sigma^{\prime}{ }^{\prime 16}$, em português, "cometo sagrado crime"), um oximoro - duas ideias diametralmente opostas

\footnotetext{
${ }^{13}$ Em tradução de David Raeburn e Oliver Thomas: "From suffering, learning" (p. 87)

14 "Claro, tu, para estes, pareces pensar, mas eu, a estes..."; em inglês, "To one side you seemed right; to the other, I did."

${ }^{15}$ Hörderlin traduz este verso assim: "Gemeinsamschwesterliches! O Ismenes Haupt!", "Oh cabeça comum e fraterna! Cabeça de Ismene!"

16 "I will commit a holy crime".
} 
(nobreza e vilania, piedade e baixeza) que se associam. A Ismene sofocliana imediatamente assinalará que Antígona é demasiado calorosa com os mortos ("frios"), insinuação muito clara de pendor necrofílico.

Há ainda dois pequenos versos de Ismene (SÓFOCLES. Ant.. v. 84 e 85), aconselhando a irmã a bem ocultar seu projeto de enterrar Polinice (“' $\alpha \lambda \lambda$ ” oṽv $\pi \rho \mu_{\eta \eta} v \dot{\sigma} \sigma \varsigma \gamma \varepsilon$

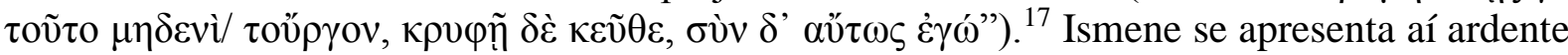
e plácida; altiva e terna; sua coragem e perspicácia são admiráveis. Recorda o vaticínio que condensa o destino trágico de sua linhagem. Há aqui uma névoa de conotações políticas, devidas às oscilações emocionais das irmãs. Antígona, ao final do Prólogo, reedita o impulso incestuoso. Ratifica a mentalidade familiar: todos privilegiam a própria família.

A segunda tarefa atribuída à Ismene moderna decorre de algo que se desvela à luz de sua nomeação. Pela etimologia, Ismene (raiz *eis, *is com o sufixo -men) é "a impetuosa, a vigorosa", o que, aparentemente, contraria a atitude da personagem grega. O paradoxo é resolvido por Pedro de Senna que, conhecendo a mântica das palavras, principalmente para o mundo antigo, desfaz o descompasso entre sema e soma, signo e corpo, no caso, da personagem que, uma vez nomeada, passa a responder pela nomeação somente nos palcos brasileiros. Habilidosamente, a peça deixa a pista de que a verossimilhança da sua heroína se encontra no ato de calar, no étimo a que ela se liga. Para tal, respalda-se na autoridade de Édipo para explicar o inesperado desencantamento da fraca Ismene (diz Creonte, na Cena 6, p. 42): "Foi seu pai que escolheu teu nome".

Ainda na esfera do páthos moderno e pós-moderno que Ismene subsume, assinalamos aqui a riqueza que a retórica visual do espetáculo contém. O cenário fixo, como o frontispício de um templo, descarrega sobre a plateia forte tensão. O painel de abertura da peça foi concebido a partir do que o historiador da arte alemão, Aby Warburg, célebre por ter demonstrado o ressurgimento do Paganismo no Renascimento italiano e pelos problemas teóricos aos quais se dedicou durante toda a vida. Na sua obra principal, a Nachleben der Antike (A sobrevivência do antigo), Warburg demonstra a persistência das imagens e ideias da Antiguidade clássica pagã ao longo da civilização europeia já cristianizada. $\mathrm{O}$ mais intrigante desdobramento da sua famosa e excêntrica Biblioteca, no centro do Instituto Warburg, foi certamente o já anteriromente mencionado Atlas de Imagens "Mnemosine", uma coleção maciça e fragmentária de imagens (com pouco ou nenhum texto), também engenhosamente concebida para ser continuamente reorganizada ${ }^{18}$. Com o projeto que homenageia a musa grega da memória, Warburg pretendia estabelecer "cadeias de transporte de imagens"; linhas de transmissão de marcas visuais através dos tempos, que carregariam consigo o páthos, emoções básicas engendradas no nascimento da civilização ocidental por ele denominadas Pathosformeln - ou "fórmulas afetivas".

Assim, Warburg designa os gestos arquetípicos ligados a emoções tais como tristeza, alegria, medo, melancolia, ódio, amor, esperança, desejo, frustração, audácia..., consagrados pela repetitividade e pela estratificação de experiências subjetivas. São imagens que condensam uma situação de caráter emocional (páthos) num cânon ao qual automaticamente remetem (Formeln), já que, de sua forma irrompe o conteúdo. Warburg, com o paradigma das Pathosformel, descreve a presença, na arte europeia, de gestos expressivos originados na Antiguidade e de sua inversão, em artistas que os retomam posteriormente: o gesto

\footnotetext{
${ }^{17}$ Mas, a ninguém segredes isso, / na calada, guarda a obra e, na mesma, fico eu"; But I know I'm pleasing those I must please most."

${ }^{18}$ O Atlas é, fundamentalmente, a tentativa de combinar filosofia e história, na análise das imagens. Fotos de pinturas, livros, recortes de jornal, materiais visuais vários etc., todos ilustrativos de temas específicos, eram fixados em pranchas com fundo negro.
} 
densamente expressivo, assim, não pode reaparecer, senão trasmudado (TOMLINSON, 2004).

Encontram-se diversas atitudes corporais e expressões gestuais, no repertório iconográfico da Antiguidade e da época helenística, em particular, que constituem fórmulas de páthos. Tais expressões figurativas encerram um dramatismo muito marcado, como estabelece o significado do páthos. O fundador da moderna iconologia, Warburg, precursor de Ernst Gombrich, Erwin Panofsky, Carlo Guinsburg e outros, propõe, à primeira vista, uma ideia que parece até ingênua, o que é desmentido pela constatação de que gestos quase convencionais se tornam fórmulas emotivas, quando a intensificação de um movimento exterior joga com elaborações interiores. Warburg associou os gestos à revelação corporal da emoção. Neles testemunhamos a expressão somática de impulsos interiores e psíquicos, a apreensão instantânea de movimentos subjetivos. Nesse sentido, as fórmulas de páthos constituem um instrumento privilegiado para o tratamento analítico das formas cinéticas e da história dos afetos. Elas também assinalam elementos de caráter antropológico, já que remontam a gestos inconscientes, anteriores aos conceitos e aos signos: recuperam uma memória corporal que traz à tona aspectos intangíveis da subjetividade. As imagens corporais de longa tradição preservam, enfim, nos gestos, os primeiros dêiticos, apontando para fenômenos de que os mesmos gestos se originam ${ }^{19}$.

Pela construção tectônica, quase dórica, do espetáculo - com signos de pureza suprema, elemental e atemporal -, a peça estabelece uma peculiar consonância com o moderno, através do aspecto mecânico de suas formas, volumétricas simples, privadas de ornamento, "puras", estritamente funcionais (pedra de toque do moderno, SETTIS, p. 41). Pelo regime acústico totalmente codificado (no sentido de obedecer a uma convenção rígida), que busca manter sob controle a emoção, desambiguizar o sentido em falas rigorosamente declamadas ou mesmo gritadas, sem apelo às modulações vocais, o ritmo absolutamente calcado no ritmo da frase, nossa peça é um objeto intercultural antigo-pós-moderno.

\section{Transtemporalidade do não-contemporâneo}

O segundo exemplo diz respeito a uma sutileza histórica. Volta à baila a questão de purificar a casa real e o solo tebanos.

\section{Ismene}

Eles querem me casar

com o comandante de Argos

Assim ele usurpa a coroa de meu tio a coroa de meu pai numa cabeça estrangeira

Ele toma a cidade em paz e poupa o povo do horror da batalha saque sangue derramado

(IPT, Cena 1, p. 29)

\section{Ismene}

\section{Em paz}

vão me fazer Rainha de Tebas

assim o trono mantém sangue tebano

meu herdeiro meu sangue

com semente de Argos (Id., p. 30)

${ }^{19}$ Assim como as palavras levam à etimologia, as Pathosformeln levam à imagogênese dos gestos. 
N'A tragédia de Ismene, o agressor argivo é um usurpador; camufla o interesse político acobertado pelo estratagema do General (ele propõe a Ismene que minta, dizendo aceitar a proposta de casamento) - manter o sangue labdácida em Tebas -, que a Princesa desvenda, mas já estava, em negativo, na peça de Sófocles. Na tragédia sofocliana dedicada à Antígona, é justamente o sangue labdácida o obstáculo que Creonte quer elidir, no acesso de Hêmon ao trono tebano. A interdição às honras fúnebres de Polinice foram um subterfúgio para afastar a descendência de Édipo do trono tebano - o interesse do tirano, de fato, era impedir o casamento de Hêmon com a labdácida. O Creonte sofocliano quer, aliás, mais do que matar Antígona: quer acabar com o míasma $(\mu i ́ \alpha \sigma \mu \alpha)$ familiar. Mortos os irmãos,

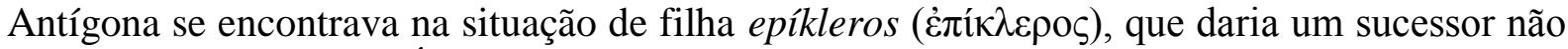
ao marido, mas ao rei Édipo, morto e sem descendência masculina (ROSENFIELD, 2000, p.40-48). Isso, Creonte não queria. Com este subtexto, a moeda de troca pelo cumprimento da sagrada lei de dar sepultamento aos cadáveres foi a morte de Antígona, camuflando a definitiva separação dos primos noivos.

Na peça brasileira, a moeda de troca pela salvação da cidade é o casamento não com um familiar (Ismene trai o esquema endogâmico e incestuoso de sua ancestralidade), mas com o inimigo, camuflando a permanência da estirpe maldita em solo tebano. As irmãs estão em perfeita correlação negativa. O heroísmo de Antígona, todavia, é sublime; mesmo pesando contra ela um inegável pendor necrofílico, uma certa dose de desejo incestuoso por Polinice, uma hýbris (őßpıs) indômita, uma língua desaforada e ainda por cima um projeto suicida (com toda a negatividade que o suicídio trazia para os gregos, visto como crime antipolítico), Antígona sai de cena com toda a majestade, exaltada pelo Coro.

A sublimidade de Ismene é totalmente diferente; ela tem a grandiosidade do pequeno (devaneia, perde-se em reminiscências da infância, Cena 3, p. 47-58); a dignidade do honestamente fraco ("Não me deixes, tio", p. 59); a consciência de si e de seu medo ("Esse é o meu medo", p. 30; "Estou com medo", p. 47): a última das princesas faz o que qualquer mulher hoje em dia faria.

\section{Coro}

Salva a tua casa

\section{Ismene}

Eu nunca quis ser rainha

esta praga cancro a coroa

eu queria evitar

Creonte - Nenhum homem de juízo quer ser rei

muita inquietude

(IPT, Cena 3, p. 52)

(...)

\section{Ismene}

Melhor não nascer

é isto o que quero para meus filhos

nunca nascer para esta vida esta família

esta maldição

(Id., p.53) 
Mas é no influxo de suas qualidades em negativo que ela se ergue, na peça brasileira, e nega a reificação das relações conjugais, o mercadejamento do seu corpo, a gravidez utilitária.

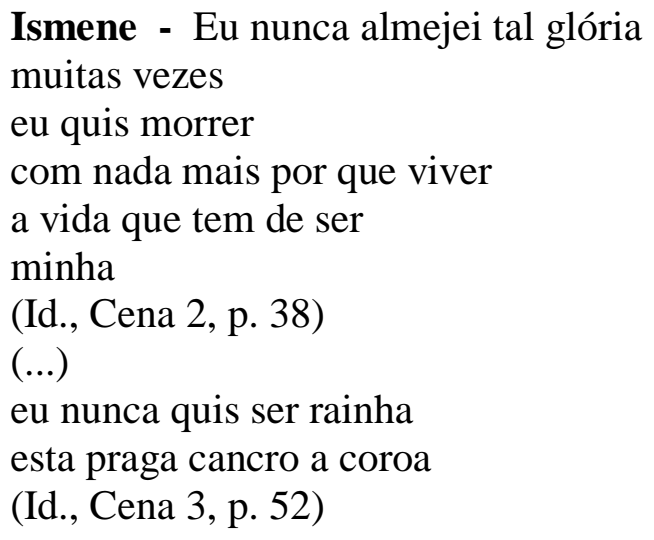

Em função destes posicionamentos, Ismene nega também a abjeção; conjura apoio para a sua decisão de não gerar filhos para a cidade caótica; sabota o plano do general (a quem hipotecara um corpo fértil e disponível) e blefa com o usurpador (diz-se pronta para o contrato matrimonial, mas foge, às escondidas, com Tirésias, os dois últimos a abandonar Tebas). Ela enfrenta e joga por terra o projeto ansiado e perdido de sua irmã (SÓFOCLES, Ant., v. 811-816),

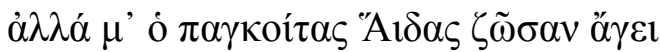

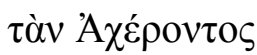

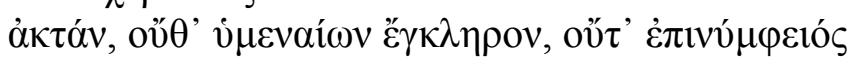

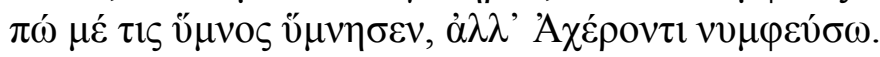 \\ mas o indolente Hades, viva me leva \\ Até o lajedo de \\ Aqueronte, sem sorte de himeneu, nem hino \\ nupcial que cantarão jamais: com Aqueronte dormirei. ${ }^{20}$
}

Ao contrário, a independente Ismene se liberta e afirma:

\title{
Ismene -
}

(...) Não vou fazer o teu dever

o dever de um homem é

defender sua cidade

General - Talvez não sobre nada para se defender

Alteza

ou ninguém para defendê-la

\footnotetext{
${ }^{20}$ Still alive, Hades, / Who makes us all

Sleep, at last, / Is leading me to

The banks of the River / Akheron. I have

No share of marriage / Rites, nor did

Any hymn of marriage / Sing me to

My wedding. / Instead my marriage will be to Akheron.
} 
Podemos nos render abrir os portões

fazer o que tebanos jamais fizeram

e tornar-nos escravos

ou lutar até a morte

e morrer como bravos tebanos já morreram

Ismene - Ou anunciar meu leito nupcial

como os generais tebanos agora querem

Como o leito de minha mãe foi anunciado

para qualquer um tomar

meu pai

gerando crianças de quem todos

se afastariam

a quem agora vós

volveis

Sim

como então foi feito

agora também quereis me casar

inventar novo rei em meu leito

inundar nossos portões com homens de Argos

inundar o meu ventre com semente de Argos

oferecer o trono ao sangue de Argos

Não

Não serei a puta da cidade

prefiro morrer

(IPT, Cena 2, p.38-39)

Por duas vezes, com a irmã e agora, com os tebanos, Ismene perdeu o timing, agiu "tarde demais". Ela não suporta a ideia de enfrentar o destino, nem quer dar continuidade à maldição. Não quer um filho maldito. Mas a imagem do tio insano, "vagando louco" (IPT, p. 89), dita-lhe a decisão: "Aceito / e se um filho vier quando o filho vier / vou matá-lo" (p. 90).

Como se vê, as situações da peça ressaltam o quanto o medo é ainda a marca do humano, na modernidade. A moral da valentia não foi suficiente para saná-lo. Daí resulta a dúvida, que se lê no monólogo final de Creonte:

\section{Creonte}

A princesa partiu com o cego

ninguém sabe o seu destino

ao certo

(p. 106)

(...) Alguns dizem que se juntaram à procissão

em fuga

que o velho cego

seu destino ligado à cidade

morreu no minuto em que o primeiro estrangeiro

pôs os pés

dentro dos grandes portões

morreu morte 

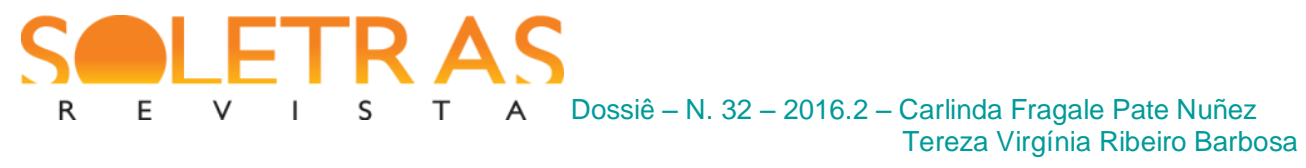

prevista

Alguns dizem que ficaram para trás
em Tebas
e esperaram que o invasor
viesse
e lutaram
resistência inútil
a não ser pela honra nome de
Tebas
uma princesa em armas
com um cego ao seu lado
morreram morte
heróica ainda que
patética

Alguns dizem que ela se matou por Tebas por seu próprio medo vergonha não ter sido o bastante dito o bastante juntou-se aos mortos que a precederam em glória vã morreu morte envergonhada ainda patética A ação máxima a máxima passividade feito irrelevante ninguém para ver sem glória morte vã

\section{Em síntese}

Assim, vimos, foi através da invenção de um enredo totalmente novo que fomos levados a identificar, no campo de evocações aberto pelo contraste com o mito antigo, sutilezas bastante bem concebidas e camufladas em suas fontes, estratégias sutis que podem ter fixado a imagem de Ismene simplesmente como o oposto complementar de Antígona - e não foi bem assim. Da mesma forma que a obra atual é capaz de projetar luz sobre a antiga, pode-se racionar mirando no sentido contrário, prospectivamente: os materiais antigos introduzidos na peça da atualidade funcionam como o elemento anacrônico, na função de tradutor cultural de problemáticas e dos padrões emotivos arcaicos que se deixam melhor capturar fora de sua abordagem usual.

A adaptação o tema de Ismene se presta a um tipo de assimilação sofisticada, pois joga com uma elaboração estética arcaizante que corresponde inversamente à dissimilação de conteúdos antigos. Em outras palavras, introduzimos aqui uma abordagem da peça de Pedro de Senna que leva em conta a presença do clássico e estrangeiro no seu equacionamento 
interno, como conteúdo e como forma de organização. Se compreendemos que se trata de uma peça brasileira que inventa um enredo protagonizado por Ismene, estamos inserindo a protagonista como estrangeira (grega) numa problemática que é camufladamente tebana e antiga, mas é explicitamente moderna e pós-moderna, discutindo o regime do medo e os modos de controle sobre as vidas e os corpos na era moderna. Se entendemos que a peça é a reexperimentação do modelo da tragédia antiga, temos de admitir que Ismene é uma personagem moderna e falante da língua portuguesa surpreendida num conflito e num contexto que lhe são totalmente estranhos - e a peça passa a ser o modo de cristalização artística das soluções possíveis perante impasses existenciais - especialmente o ceticismo moderno perante o medo ancestral que humanamente nos constitui. As duas situações combinam, no regime de construção estética do texto e do espetáculo que lhe correspondeu. Se estivermos certos, teremos confirmado nossas hipóteses:

1- de que obras de extração clássica constituem formas ativas de transferências culturais, ainda que as teorias sobre as trocas entre culturas determinem a reciprocidade de operação - o que, efetivamente, não pode acontecer nas relações do presente com o passado.

2- de que os mediadores desta transferência dificilmente podem ser depreendidos sem uma análise da história cultural dos objetos em correlação.

Às complexidades devolvidas à figura mítica exumada por Pedro de Senna acrescentam-se as problemáticas do sistema de recepção, operando um contraponto entre estruturas múltiplas e díspares que se imbricam. A obra, ao mesmo tempo, dá acesso a uma outra cultura, distante no tempo e muito diferente, com formas de representação e estruturas imaginárias inteiramente distintas das atuais, mas as adota como meio através do qual o contexto de acolhimento se espelha e se pensa.

Inserida numa surpreendente malha compositiva, numa rede trans-histórica do teatro e no enclave em que ocorrem transferências culturais inusitadas, A Tragédia de Ismene revoga o rótulo de simplicidade atribuído à figura mítica, para, bem ao contrário, encarnar complexidades antigas e atuais. $\mathrm{O}$ antigo e o novo se encontram, portanto, mantidos e respeitados como não-contemporâneos.

\section{REFERÊNCIAS}

BRANDÃO, Junito de S. Dicionário mítico-etimológico da Mitologia grega. Petrópolis: Vozes, 1991.

DEMAND, Nancy. Birth, Death, and Motherhood in Classical Greece. Baltimore: The Johns Hopkins University Press, 1994.

D’AMARAL, Márcio Tavares. "Sobre o tempo: considerações intempestivas”. In: Doctors, Márcio. (org.). Tempo dos tempos. Rio de janeiro: Jorge Zahar Ed., 2003, p. 15-32.

DODDS. E. R. Os gregos e o irracional. Tradução Leonor Santos de Carvalho. Lisboa: Gradiva, 1988.

ESPAGNE, Michel. Les Transfers culturels franco-allemands. Paris: PUf, 1999.

ÉSQUILO. The Agamemnon of Aeschylus: A Commentary for Students. David RAEBURN and Oliver THOMAS (ed.). Oxford: University Press, 2011. 
EURIPIDES. Medea. Transleted by Diane Arnson Svarlien; introduction and notes by Robin Mitchell-Boyask. Indianopolis: Hackett Publishing Company, 2008.

Editorial, 2013. Medeia de Eurípides. Direção de tradução de Tereza Virgínia Ribeiro, Ateliê

HEGEL, G. W. F.. Estética I. Trad. Marco Aurélio Werle e Oliver Tolle. São Paulo: Edusp, 2000.

HUNGER, Herbert. Lexikon der griechischen und römischen Mythologie. Hamburg: Rowohlt, 1985.

MOSER, Walter. O Estudo do não-contemporâneo: Historiofagia ou historiografia. Trad. Viviam Morello e Alena Ciulla. Porto Alegre: PG-Letras da PUCRS, 1993.

NOVAES, Adauto (org.). Os Sentidos da paixão. São Paulo: Companhia das Letras, 1987. RITSOS, Yannis. "Ismene," in The Fourth Dimension, ed. Yannis Ritsos. Princeton University Press, 1993, p. 191-214.

ROSENFIELD, Kathrin H. Antígona - de Sófocles a Hölderlin: por uma filosofia "trágica" da literatura. Porto Alegre: LP\&M, 2000.

SENNA, Pedro de. A Tragédia de Ismene, Princesa de Tebas. Rio de Janeiro: Móbile, 2013. SETTIS, Salvatore. El futuro de lo clásico. Tradução Andrés Soria Olmedo. Mardi: Abada Ed., 2006.

SOPHOCLE. Les Trachiniennes / Antigone. Trad. Paul Mazon. Paris: Belles Lettres, 1967. - Antigone, Oedipus The King \& Electra. Translated by H. D. F. Kitto Edited with an Introduction and Notes by Edith Hall. Oxford: University Press, 1962/1994. . Antigone. Edited by Mark Griffith. Cambridge, University Press, 1999.

TOMLINSON, Gary. "Five pictures of pathos". In: Paster, G. K.; Rowe, K. \& FloydWilson. M. (Ed.). Reading the early modern passions. Essays in the cultural history of emotion. Philadelphia: University of Pennsylvania Press, 2004.

TOSI, Renzo. Dicionário de Sentenças Latinas e Gregas. Trad. de Ivone Castilho Benedetti. São Paulo: Martins Fontes, $1996 .$.

VERNANT, Jean-Pierre. Mito e pensamento entre os gregos. Trad. Haiganuch Sorian. São Paulo: Difel, 1993.

WARBURG, Aby. Atlas Mnemosyne de Imagens da Cultura. Trad. Joaquín Chamorro Mielke. Madri: AKAL, 2010.

Links

A TRAGÉDIA DE ISMENE. In:- http://www.youtube.com/watch?v=oG9thqjXW1g . Acesso em 15/10/2012.

SHAKESPEARE NAVIGATORS. http://shakespeare-navigators.com/hamlet/H15.html Acesso em 15/10/2012.

ANTIGONE / ISMENE - the tragedy of moral relativism de Milena Bogavac. In: http://www.kosztolanyi.org/en/gallery/7-antigone-ismene-the-tragedy-of-moral-relativism/ Acesso em 20/09/2016.

ISMENE de Jeremy Menekseoglu: http://dreamtheatrecompany.com/Ismene.html Acesso em 20/09/2016.

Ismene's(a)Wake de Miriam Wolodarki. In: http://www.senseobject.com/ismene/ Acesso em 20/09/2016 


\begin{abstract}
This study focus on Pedro Senna's The tragedy of Ismene, Princess of Thebes, which debuted in 2007 and was published in 2013. The play won the 1st prize by the popular jury, in the "Brazil on Stage Selection 2006", a drama contest for new authors, promoted by the Bank of Brazil Cultural Center. It was performed the following year and directed by award-winner Moacir Chaves. Our method, the intercultural approach, fits a specific type of comparativism, which, without neglecting the existence of correlations and parallelisms, emphasizes the role of untimeous anachronism adopted as an aesthetic procedure with artistic results. It is the apprehension of social knowledge that is expressed in discourse, in terms of cultural contexts. Besides the mentioned theoretical apparatus, we also resort to Aby Warburg's theorizing and his concept of Pathosformel, i.e. the "affective formulas."
\end{abstract}

Keywords: Pedro de Senna, Sophocles, Ismene, Classical reception.

Recebido em: 30 de setembro de 2016.

Aprovado em: 05 de dezembro de 2016. 